JPPKMI 2 (1) (2021) 67-75
JURNAL PENELITIAN DAN PENGEMBANGAN
KESEHATAN MASYARAKAT INDONESIA
https://journal.unnes.ac.id/sju/index.php/jppkmi

\title{
Keputusan Pemilihan Pelayanan Pengobatan Ditinjau dari Karakteristik Individu dan Aksesibilitas
}

\author{
Lisa Fitriani ${ }^{1} \bowtie$, Aprilia Artati Nur ${ }^{1}$, Rahayu $^{1}$, Raudatul Jinan $^{1,}$ Rizka Elma Selviana $^{1}$, \\ Fauzie Rahman ${ }^{2}$, Nur Laily ${ }^{2}$
}

${ }^{1}$ Mahasiswa Peminatan Administrasi Kebijakan Kesehatan, Program Studi Kesehatan Masyarakat, Fakultas Kedokteran, Universitas Lambung Mangkurat

${ }^{2}$ Departemen Administrasi Kebijakan Kesehatan, Program Studi Kesehatan Masyarakat, Fakultas Kedokteran, Universitas Lambung Mangkurat

\begin{abstract}
Info Artikel
Abstrak

Sejarah Artikel:

Diterima 8 Mei 2021

Disetujui 11 Juni 2021

Dipublikasi 12 Juni 2021

Penelitian ini bertujuan untuk mengetahui hubungan antara usia, pendidikan, status pekerjaan, dan aksesibilitas pelayanan dengan keputusan pemilihan pelayanan pengobatan di masyarakat. Penelitian ini dilakukan secara online menggunakan metode kuantitatif dengan desain studi cross sectional. Instrument yang digunakan adalah kuesioner bentuk google form. Pengumpulan data dilakukan melalui WhatsApp pada bulan April-Mei tahun 2021 dengan wilayah penelitian masyarakat yang tinggal di Kalimantan

Keywords:

Health Services, Treatment Selatan. Sampel yang digunakan pada penelitian ini sebanyak 103 Responden. Analisis data dilakukan menggunakan analisis univariat dan analisis bivariat. Hasil uji chi-square dalam penelitian ini, menunjukan nilai $\mathrm{p}$ dari variabel usia, pendidikan, status pekerjaan dan aksesibilitas adalah 0,039, 0,537, 0,145 dan 0,020 . Sehingga dapat disimpulkan bahwa ada hubungan yang signifikan antara usia dan aksesibilitas dengan keputusan pemilihan pelayanan pengobatan. Namun tidak ada hubungan yang signifikan antara pendidikan dan status pekerjaan dengan keputusan pemilihan pelayanan pengobatan. Oleh karena itu, diperlukan pemerataan pembangunan, meningkatkan kualitas mutu pelayanan,

$U R L:$ akreditasi, meningkatkan teknologi informasi, tata kelola fasilitas yang maksimal, peningkatan kualitas https://iournal.unnes.ac. d/sju/index.php/ippkmi Larticle/view/47366 dan kuantitas SDM kesehatan, melengkapi sarana prasarana, dan meningkatkan keterlibatan masyarakat.
\end{abstract}

\begin{abstract}
This study aims to determine the relationship between age, education, employment status, and accessibility of services with the decision to choose treatment services in the community. This research was conducted online using quantitative methods with a cross sectional study design. The instrument used is a google form questionnaire. Data collection was carried out via WhatsApp in April-May 2021 with the research area of people living in South Kalimantan. The sample used in this study were 103 respondents. Data analysis was performed using univariate analysis and bivariate analysis. The results of the chi-square test in this study, showed the p-values of the variables of age, education, employment status and accessibility were 0.039, 0.537, 0.145 and 0.020. So it can be concluded that there is a significant relationship between age and accessibility with the decision to choose treatment services. However, there is no significant relationship between education and employment status with decisions in choosing treatment. Therefore, it is necessary to develop equitable development, improve the quality of service quality, accreditation, improve information technology, maximum facility management, increase the quality and quantity of health human resources, complete infrastructure facilities, and increase community involvement.
\end{abstract}

(C) 2021 Universitas Negeri Semarang

$凶$ Alamat korespondensi:

J1. A. Yani No.160, Loktabat Sel., Kec. Banjarbaru Selatan,

Kota Banjar Baru, Kalimantan Selatan 70714

E-mail: $\underline{\text { isaftrn@gmail.com }}$ 


\section{PENDAHULUAN}

Kesehatan merupakan hal yang penting sehingga harus dijaga, diupayakan dan disadarkan. Selain itu, dengan meningkatkan derajat kesehatan masyarakat berarti juga meningkatkan sumber daya manusia (SDM) di negara tersebut. Sebagai unit pelayanan kesehatan tingkat pertama dan terdepan dalam sistem pelayanan kesehatan, puskesmas melakukan upaya kesehatan wajib dan upaya kesehatan pilihan yang disesuaikan dengan kondisi, kebutuhan, tuntutan, kemampuan dan inovasi serta kebijakan pemerintah daerah setempat (Irawan and Ainy, 2018). Sebagai pusat pelayanan kesehatan primer, keterjangkauan dan kemudahan akses ke sarana pelayanan kesehatan sangat diperlukan sebab mempengaruhi keberhasilan puskesmas memberikan pelayanan kesehatan (Riskesdas, 2018).

Menurut Notoatmodjo (2007), pencarian metode pengobatan terkait dengan respons masing-masing individu apabila sakit serta pelayanan kesehatan yang dibutuhkan. Respons tersebut antara lain: tindakan mengobati sendiri, mencari fasilitas pengobatan tradisional, mencari pengobatan dengan membeli obat ke warung/toko, mencari pengobatan ke fasilitasfasilitas modern yang diadakan oleh pemerintah atau lembaga kesehatan swasta. Hasil Riskesdas tahun 2018 menyatakan bahwa kemudahan akses ke sarana pelayanan kesehatan berhubungan dengan jarak tempat tinggal dan waktu tempuh ke sarana kesehatan. Dari segi waktu tempuh ke sarana pelayanan kesehatan $67,2 \%$ penduduk dapat mencapai sarana pelayanan kesehatan kurang atau sama dengan 15 menit dan $23,6 \%$ dapat mencapai dengan waktu 16-30 menit, sedangkan sisanya memerlukan waktu lebih dari setengah jam untuk mencapai sarana kesehatan. Sedangkan dari jarak menunjukkan bahwa 94,1\% Rumah Tangga berada kurang atau sama dengan $5 \mathrm{~km}$ dari sarana pelayanan kesehatan dan hanya $6 \%$ yang berjarak lebih dari $5 \mathrm{~km}$ (Riskesdas, 2018).

Rendahnya penggunaan fasilitas kesehatan sering disebabkan oleh faktor jarak antara fasilitas tersebut dengan masyarakat yang terlalu jauh (baik jarak secara fisik maupun sosial), tarif yang tinggi, pelayanan yang tidak memuaskan dan sebagainya. Terdapat beberapa faktor yang mempengaruhi tingkat pemanfaatan pelayanan kesehatan yaitu faktor yang berasal dari penyedia layanan kesehatan dan faktor dari masyarakat pengguna pelayanan kesehatan. Tiga faktor dari penyedia layanan kesehatan adalah fasilitas pelayanan, biaya pelayanan, dan jarak, sedangkan dua faktor dari masyarakat pengguna pelayanan kesehatan adalah faktor pendidikan dan status sosial ekonomi masyarakat (Mamik, 2013).

Berdasarkan penelitian Napirah (2016) terhadap 69 responden tentang faktor yang berhubungan dengan pemanfaatan pelayanan kesehatan, terdapat hubungan antara tingkat pendidikan dengan pemanfaatan pelayanan kesehatan. Tiga kategori utama dalam pemanfaatan pelayanan kesehatan menurut teori Andersen (1975), yaitu faktor Predisposisi (jenis kelamin, usia, status perkawinan, pendidikan, status pekerjaan, suku, dan kepercayaan kesehatan), karakteristik kemampuan (penghasilan, asuransi, kemampuan membeli jasa pelayanan kesehatan, pengetahuan tentang kebutuhan pelayanan kesehatan, adanya sarana pelayanan kesehatan, waktu tunggu pelayanan serta aksesibilitasnya dan ketersediaan tenaga kesehatan), dan karakteristik kebutuhan (penilaian individu, dan penilaian klinik terhadap suatu penyakit). Sedangkan menurut teori Dever (1984) faktorfaktor lain yang mempengaruhi pemanfaatan pelayanan kesehatan, yaitu faktor provider (pelayanan kesehatan, dan kemudahan informasi) (Fatimah and Indrawati, 2019).

Pemanfaatan pelayanan kesehatan adalah penggunaan fasilitas pelayanan kesehatan yang disediakan baik dalam bentuk rawat jalan, rawat inap, kunjungan rumah oleh petugas kesehatan ataupun bentuk kegiatan-kegiatan lain dari pemanfaatan pelayanan kesehatan tersebut. Pelayanan kesehatan merupakan hak setiap orang yang dijamin dalam Undang-Undang Dasar 1945 untuk melakukan upaya peningkatan derajat kesehatan baik 
perseorangan, maupun kelompok atau masyarakat secara keseluruhan (Sutana, 2021). Menurut Anderson dan Newman (1979) dalam tujuan dari pemanfaatan pelayanan kesehatan adalah: (1) Menggambarkan hubungan antara faktor penentu dari pemanfaatan pelayanan kesehatan; (2) Perencanaan kebutuhan masa depan atau target pelayanan kesehatan; (3) Menentukan adanya ketidakseimbaangan pelayanan dari pemanfaatan pelayanan kesehatan (Yulianti, B.M and Indraswari, 2021).

Penelitian Naomi (2018) menyatakan bahwa sebanyak $14,3 \%$ penduduk dengan tempat tinggal jauh selalu memanfaatkan puskesmas sedangkan penduduk yang bertempat tinggal dekat dengan puskesmas dan selalu memanfaatkan puskesmas yaitu $(51,9 \%)$. Artinya faktor jarak dan transportasi menjadi kendala bagi masyarakat untuk menjangkau puskesmas sehingga kunjungan masyarakat yang tempat tinggalnya dekat lebih banyak dari penduduk yang tempat tinggalnya jauh (Naumi, 2018).

Perbedaan antara penelitian ini dengan penelitian sebelumnya yaitu penelitian ini menggunakan modifikasi antara teori Andersen sistem kesehatan (health system model) dan teori Dever utilisasi pelayanan kesehatan. Perbedaan lain pada penelitian ini adalah cara pengumpulan data primer yang menggunakan kuesioner yang diolah menggunakan google form karena kondisi yang masih pandemik COVID19 sehingga google form disebar melalui via WhatsApp pada bulan April-Mei tahun 2021 dengan wilayah penelitian masyarakat yang tinggal pada daerah aliran sungai di Provinsi Kalimantan Selatan. Penelitian ini bertujuan untuk mengetahui hubungan antara usia, pendidikan, status pekerjaan, dan aksesibilitas pelayanan dengan keputusan pemilihan pelayanan pengobatan di masyarakat.

\section{METODE}

Penelitian ini dilakukan secara online menggunakan metode kuantitatif dengan desain studi cross sectional menggunakan kuesioner dalam bentuk google form karena kondisi yang masih pandemik COVID-19, sehingga google form disebar melalui WhatsApp. Penelitian ini dilaksanakan pada bulan April-Mei 2021, pada masyarakat yang tinggal di daerah aliran sungai Provinsi Kalimantan Selatan sebagai wilayah penelitian. Pendekatan kuantitatif digunakan untuk mengetahui hubungan antara variabel bebas yaitu usia, pendidikan, status pekerjaan dan aksesibilitas pelayanan pengobatan dan variabel terikat yaitu keputusan pemilihan pelayanan pengobatan. Teknik sampling yang digunakan adalah purposive sampling, dengan kriteria inklusi yaitu masyarakat yang tinggal pada daerah aliran sungai di Provinsi Kalimantan Selatan, berusia minimal 18 tahun dan pernah menggunakan pelayanan kesehatan. Sampel yang digunakan pada kegiatan ini adalah 103 Responden.

Kegiatan ini dilakukan dengan cara pengumpulan data primer. Data primer pada penelitian ini diperoleh dari kumpulan jawaban responden dari kuisioner yang sebelumnya sudah dibagikan melalui google form. Dalam penyajian data terdapat dua analisis yang dilakukan yaitu analisis univariat untuk mendapatkan data tentang distribusi frekuensi dari masing-masing variabel secara terpisah, baik, maupun variabel bebas. Serta analisis bivariat untuk menjelaskan hubungan dua variabel yaitu antara variabel bebas dengan variabel terikat, uji statistik yang digunakan adalah uji chi-square dengan tingkat kepercayaan 95\%. Jika asumsi tidak terpenuhi maka menggunakan uji fisher exact. Apabila uji statistik dengan $p$-value $<\alpha=0,05$, maka dikatakan bahwa ada hubungan antara dua variabel tersebut.

\section{HASIL DAN PEMBAHASAN}

Hasil pengumpulan data didapatkan 103 responden sesuai perhitungan sampel. Hasil penelitian akan terbagi menjadi 2 jenis yaitu analisis univariat dan bivariat. Hasil analisis univariat akan menghasilkan data distribusi frekuensi masing-masing variabel. Hasil analisis bivariat dengan menggunakan desain penelitian cross sectional dan uji statistik chi-square pada 
Tabel 1. Distribusi Frekuensi Karakteristik Responden

\begin{tabular}{lcc}
\hline Jenis Data & Frekuensi & Persentase (\%) \\
\hline Usia & & \\
Produktif & 86 & 83,5 \\
Non Produktif & 17 & 16,5 \\
Pendidikan & 28 & 27,1 \\
Pendidikan Tinggi (Perguruan tinggi) & 75 & 72,8 \\
Pendidikan Rendah (SMA-SMP-SD) & & \\
Status Pekerjaan & 35 & 34 \\
Bekerja & 68 & 66 \\
Tidak Bekerja & & \\
Jarak & 51 & 49,5 \\
$\leq 3$ km & 52 & 50,5 \\
$>3$ km & & \\
Waktu Tempuh & 77 & 74,8 \\
$\leq 30$ menit & 26 & 25,2 \\
$>30$ menit & & \\
Biaya & 51 & 49,5 \\
$\leq$ Rp 10.000,- & 52 & 50,5 \\
$>$ Rp 10.000,- & & \\
Aksesibilitas Pelayanan Pengobatan dengan pelayanan kesehatan & 35 \\
Mudah & 35 & 69,1 \\
Sulit & 72 & 8,7 \\
Keputusan Pemilihan Pelayanan Pengobatan & & 91,3 \\
Pengobatan Tradisional & 9 & \\
Pengobatan di Fasilitas Kesehatan & 94 & \\
\hline$\quad$ Sumber: Dat Primer Tahun 2021 &
\end{tabular}
Sumber: Data Primer Tahun 2021

SPSS dan akan menjelaskan hubungan antara usia, pendidikan, status pekerjaan dan aksesibilitas pelayanan pengobatan dengan keputusan pemilihan pelayanan pengobatan di masyarakat.

Tabel 1 menunjukkan bahwa sebagian besar usia responden masuk pada kategori produktif yaitu 86 responden $(83,5 \%)$, dan responden dengan kategori pendidikan rendah yaitu sebanyak 75 responden $(72,8 \%)$ yang terdiri dari SD-SMP-SMA. Responden sebagian besar tidak bekerja yaitu sebanyak 68 responden $(66 \%)$, sedangkan responden yang bekerja sebanyak 35 responden (34\%) dengan jenis pekerjaan seperti pedagang/wiraswasta, PNS, TNI/Polri, pegawai swasta, petani, buruh, dan analis kesehatan. Semua responden (100\%) menyatakan bahwa mereka tinggal pada daerah yang memiliki fasilitas kesehatan. Berdasarkan temuan tersebut sebagian besar (94 responden/91,2\%) lebih memilih melakukan pengobatan ke fasilitas kesehatan seperti puskesmas, klinik, rumah sakit ataupun klinik dokter dan bidan. Jarak responden ke pelayanan kesehatan sebagian besar pada kategori sejauh > $3 \mathrm{~km}$ yaitu sebanyak 52 responden (50,5\%) sedangkan waktu yang diperlukan ke pelayanan kesehatan masuk dalam kategori tidak lama (memerlukan waktu $\leq 30$ menit) yaitu sebanyak 77 responden (74,8\%). Sementara itu, aksesibilitas pelayanan kesehatan sebagian besar (72 responden/69,9\%) masuk dalam kategori sulit mendapatkan pelayanan kesehatan. Sedangkan biaya yang dikeluarkan responden untuk menuju ke pelayanan kesehatan cukup besar ( $>\mathrm{Rp} 10.000,-)$, yaitu sebanyak 52 responden $(50,5 \%)$.

Hubungan Antara Usia dengan Keputusan Pemilihan Pelayanan Pengobatan

Tabel 2 menunjukkan bahwa 81 
Tabel 2. Hubungan Antara Usia, Pendidikan, Status Pekerjaan dan aksesibilitas dengan Keputusan Pemilihan Pelayanan Pengobatan

\begin{tabular}{|c|c|c|c|c|c|c|}
\hline \multirow[t]{2}{*}{ Variabel } & \multicolumn{2}{|c|}{$\begin{array}{l}\text { Keputusan } \\
\text { Pengobatan }\end{array}$} & \multicolumn{2}{|c|}{ Pemilihan } & \multirow[t]{2}{*}{ Total } & \multirow[t]{2}{*}{$p$-value } \\
\hline & Faskes & $\%$ & Tradisional & $\%$ & & \\
\hline \multicolumn{7}{|l|}{$\overline{\text { Usia }}$} \\
\hline Produktif & 81 & 94,2 & 5 & 5,8 & 86 & 0,039 \\
\hline Non-produktif & 13 & 76,5 & 4 & 23,5 & 17 & \\
\hline $\begin{array}{l}\text { Total } \\
\text { Pendidikan }\end{array}$ & 94 & 91,3 & 9 & 8,7 & 103 & \\
\hline Tinggi & 26 & 92,9 & 2 & 7,1 & 86 & 0.537 \\
\hline Rendah & 68 & 90,7 & 7 & 9,3 & 17 & \\
\hline Total & 94 & 91,3 & 9 & 8,7 & 103 & \\
\hline \multicolumn{7}{|l|}{ Status } \\
\hline \multicolumn{7}{|l|}{ Pekerjaan } \\
\hline Bekerja & 30 & 85,7 & 5 & 14,3 & 35 & 0,145 \\
\hline Tidak bekerja & 64 & 94,1 & 4 & 5,9 & 68 & \\
\hline $\begin{array}{l}\text { Total } \\
\text { Aksesibilitas }\end{array}$ & 91 & 88,3 & 9 & 11,7 & 103 & \\
\hline Mudah & 25 & 80,6 & 6 & 19,4 & 31 & 0,020 \\
\hline Sulit & 69 & 95,8 & 3 & 4,2 & 72 & \\
\hline Total & 94 & 91,3 & 9 & 8,7 & 103 & \\
\hline
\end{tabular}

\section{Sumber: Data Primer Tahun 2021}

responden $(94,2 \%)$ yang berusia produktif memilih layanan pengobatan di fasilitas kesehatan, sedangkan yang memilih layanan pengobatan tradisional hanya sebanyak 5 responden (5,8\%). Sebanyak 13 responden (76,5\%) yang non-produktif memilih pelayanan pengobatan fasilitas kesehatan, sedangkan yang memilih pelayanan pengobatan tradisional hanya sebanyak 4 responden $(23,5 \%)$. Hasil uji chi-square menunjukkan $p$-value $=0,039(\mathrm{p}<0,05)$ yang artinya ada hubungan antara usia dengan keputusan pemilihan pelayanan pengobatan.

Penelitian ini sejalan dengan penelitian Yulianti tahun 2013 yang menyatakan bahwa responden yang memiliki kategori usia dewasa awal yang paling banyak memanfaatkan pelayanan kesehatan secara medis (Yuliana, 2013). Begitupula pada penelitian Ratnasari tahun 2018 disebutkan bahwa ada hubungan yang bermakna antara usia dengan pemilihan pelayanan pengobatan dengan $p$-value $<0,001$ (Ratnasari, 2018). Fakta lain ditemukan bahwa usia produktif mayoritas lebih memilih fasilitas kesehatan sebanyak 81 responden $(94,2 \%)$ dibandingkan pengobatan tradisional. Hasil ini bertentangan dengan penelitian Sampeluna tahun 2013 yang menyatakan bahwa tidak ada hubungan usia dengan pemanfaatan pelayanan kesehatan di RSUD Lakipadada Kabupaten Tana Toraja. Berdasarkan temuan tersebut responden yang termasuk dalam kategori usia dewasa dan memanfaatkan pelayanan kesehatan sebanyak 73 responden (71,6 \%) dan tidak memanfaatkan sebanyak 29 responden $(28,4 \%)$, dan termasuk kategori usia tua dan memanfaatkan pelayanan kesehatan sebanyak 210 responden $(71,2 \%)$ dan tidak memanfaatkan sebanyak 85 responden (28,8\%) (Sampeluna, Balqis and Hamzah, 2013).

\section{Hubungan Antara Pendidikan dengan Keputusan Pemilihan Pelayanan Pengobatan}

Tabel 2 menunjukkan bahwa 26 responden $(92,9 \%)$ yang berpendidikan tinggi memilih pelayanan pengobatan di fasilitas kesehatan, sedangkan yang memilih pelayanan pengobatan tradisional hanya sebanyak 2 responden $(7,1 \%)$. Sebanyak 68 responden $(90,7 \%)$ yang berpendidikan rendah memilih pelayanan pengobatan fasilitas kesehatan, sedangkan yang memilih pelayanan pengobatan tradisional hanya sebanyak 7 responden $(9,3 \%)$. Hasil uji chi-square menunjukkan $p$-value $=0,537$ $(\mathrm{p}>0,05)$ yang artinya tidak ada hubungan antara pendidikan terakhir dengan keputusan 
pemilihan pelayanan pengobatan.

Hasil penelitian ini sejalan dengan penelitian Kurniasih tahun 2018 yaitu hasil uji analitik menunjukkan hasil p-value 0.058 , atau probabilitas diatas 0.05 (tingkat signifikansi), maka H0 diterima. Sehingga tidak terdapat hubungan antara faktor pendidikan dengan pemilihan fasilitas kesehatan. Ada faktor lain di luar pendidikan yang mempengaruhi pemilihan fasilitas kesehatan (Kurniasih I, 2018). Girma (2011) menyampaikan faktor pengetahuan atau informasi yang telah didapat diharapkan memberikan motivasi untuk dapat menentukan layanan kesehatan dan memanfaatkan fasilitas kesehatan yang tersedia yang ini tidak ada keterkaitan dengan tingkat pendidikan. Hal ini senada dengan hasil penelitian Debra dkk (2015) yang menunjukkan bahwa tidak terdapat hubungan antara karakteristik responden yang terdiri atas jenis kelamin, usia, pendidikan, status pekerjaan dan pendapatan dengan Pemanfaatan Pelayanan Kesehatan di Puskesmas. Karakteristik masyarakat pengguna pelayanan kesehatan di RS dan Puskesmas memang hampir sama serta khusus pada pelayanan kesehatan di Puskesmas telah dimanfaatkan oleh hampir semua elemen masyarakat dengan tingkat pendidikan, status pekerjaan dan pendapatan keluarga yang bervariasi (Rumengan, Januraga and Indrayathi, 2019). Fakta lain ditemukan bahwa pendidikan rendah juga cenderung memilih fasilitas kesehatan untuk pengobatan yaitu sebanyak 68 responden $(90,7 \%)$.

Hasil penelitian ini bertentangan dengan penelitian Tampi (2016) yang menyatakan bahwa terdapat hubungan antara bukti fisik dengan kepuasan pasien karena nilai p-value $0,002<\alpha(0,05)$ dan untuk nilai Odds Ratio pada pendidikan yaitu 4,144 , yang berarti pendidikan tinggi akan 4,1 kali lipat kepala keluarga akan memanfaatkan pelayanan kesehatan dibandingkan dengan tidak memanfaatkan pelayanan kesehatan di rumah sakit. Berdasarkan temuan, responden yang memanfaatkan pelayanan yaitu sebanyak 47 responden terdiri dari 10 responden $(21,3 \%)$ memiliki pendidikan rendah dan 37 responden
(78,7\%) memiliki pendidikan tinggi, dan total responden yang tidak memanfaatkan yaitu sebanyak 53 responden terdiri dari 28 responden $(52,8 \%)$ memiliki pendidikan rendah dan 25 responden $(47,2 \%)$ memiliki pendidikan tinggi (Tampi, 2016). Pendidikan merupakan salah satu faktor sosio-ekonomi konsumen yang mempengaruhi individu dalam memanfaatkan pelayanan kesehatan. Pendidikan akan mempengaruhi kesadaran individu akan pentingnya arti sehat bagi diri dan lingkungan, sehingga dapat mendorong kebutuhan akan pelayanan kesehatan dan pemilihan terhadap pelayanan kesehatan. Semakin tinggi pendidikan seseorang, maka secara relatif utilisasi terhadap pelayanan kesehatan semakin tinggi (Notoatmodjo, 2007).

\section{Hubungan Antara Status Pekerjaan dengan Keputusan Pemilihan Pelayanan Pengobatan}

Tabel 2 menunjukkan bahwa 30 responden $(85,7 \%)$ yang bekerja memilih pelayanan pengobatan di fasilitas kesehatan, sedangkan yang memilih pelayanan pengobatan tradisional hanya sebanyak 5 responden (14,3\%). Sebanyak 64 responden (94,1\%) yang tidak bekerja memilih pelayanan pengobatan fasilitas kesehatan, sedangkan yang memilih pelayanan pengobatan tradisional hanya sebanyak 4 responden (5,9\%). Hasil uji chi-square menunjukkan $p$-value $=0,145(\mathrm{p}>0,05)$ yang artinya tidak ada hubungan antara status pekerjaan dengan keputusan pemilihan pelayanan pengobatan.

Hasil penelitian ini sejalan dengan penelitian Irawan (2018) menunjukkan bahwa status pekerjaan tidak berhubungan dengan pemanfaatan pelayanan kesehatan. Pada kelompok orang yang bekerja ataupun tidak memiliki pekerjaan tidak akan selalu berhubungan dengan pemanfaatan pelayanan kesehatan karena pola pikir dan motivasi yang cenderung berubah-ubah membuat seseorang akan memilih pengobatan atau pelayanan kesehatan lainnya (Irawan and Ainy, 2018). Begitu pula dengan penelitian yang dilakukan oleh Tampi (2016) hasil penelitiannya menunjukkan bahwa tidak ada hubungan antara status pekerjaan dengan pemilihan pelayanan 
kesehatan dengan $p$-value $0,976<\alpha(0,05)$. Dari total 47 responden terdapat 14 responden $(45,0 \%)$ yang tidak bekerja dan 33 responden $(48,0 \%)$ yang bekerja, dan total responden yang tidak memanfaatkan pelayanan kesehatan yaitu sebanyak 53 responden terdiri dari 17 responden $(55,0 \%)$ yang tidak bekerja dan 36 responden (52,0\%) yang bekerja (Tampi, 2016).

Hasil penelitian ini bertentangan dengan penelitian Hussein, Musiana (2012) dalam Londo (2017) menunjukkan bahwa faktor status pekerjaan sangat berpengaruh terhadap pemanfaatan pelayanan kesehatan di puskesmas (Londo, Tucunan and Maramis, 2017). Begitu pula dengan penelitian yang dilakukan oleh Pangemanan (2014) bahwa hasil uji chi-square menghasilkan nilai probabilitas sebesar 0,003. Hal tersebut menunjukkan bahwa terdapat hubungan antara status pekerjaan dan pemanfaatan pelayanan kesehatan. Begitupun menurut Buhaeni dkk (2013) dalam Pangemanan (2014) didapatkan nilai p-value 0,041 yang berarti ada hubungan antara pekerjaan dengan pemanfaatan pelayanan antenatal. Berdasarkan temuan diketahui bahwa 48 responden yang memanfaatkan pelayanan terdapat 39 reponden $(62,9 \%)$ yang tidak bekerja dan terdapat 9 responden $(36,0 \%)$ yang bekerja. Sedangkan dari 39 responden yang kurang memanfaatkan pelayanan terdapat 16 responden $(64,0 \%)$ yang bekerja dan terdapat 23 responden $(37,1 \%)$ yang tidak bekerja (Jane M.Pangemanan, Nova H. Kapantow, 2014). Pekerjaan merupakan salah satu faktor sosioekonomi konsumen yang turut berperan mempengaruhi individu dalam pelayanan kesehatan. Pekerjaan merupakan salah satu faktor pendukung yang mempengaruhi seseorang dalam memanfaatkan pelayanan kesehatan. Seseorang yang bekerja memiliki kecenderungan lebih tinggi untuk memanfaatkan pelayanan kesehatan dibandingkan dengan seseorang yang tidak bekerja (Londo, Tucunan and Maramis, 2017).

Hubungan Antara Aksesabilitas dengan Keputusan Pemilihan Pelayanan Pengobatan

Tabel 2 menunjukkan bahwa sebanyak 25 responden $(80,6 \%)$ yang mudah dalam mengakses pelayanan pengobatan di fasilitas kesehatan, sedangkan sebanyak 6 responden $(19,4 \%)$ yang mudah dalam mengakses pelayanan pengobatan tradisional. Sebanyak 69 responden (95,8\%) yang sulit mengakses pelayanan pengobatan fasilitas kesehatan, sedangkan 9 responden $(8,7 \%)$ yang sulit mengakses pelayanan pengobatan tradisional. Hasil uji chi-square menunjukkan $p$-value $=0,020$ $(\mathrm{p}<0,05)$ yang artinya ada hubungan antara aksesibilitas pelayanan pengobatan dengan keputusan pemilihan pelayanan pengobatan.

Hasil ini sejalan dengan penelitian yang dilakukan oleh Fatimah (2019) menunjukkan bahwa terdapat hubungan antara aksesibilitas dengan pemilihan pelayanan kesehatan karena nilai $p$-value $0,000<0,05 \quad$ (Fatimah and Indrawati, 2019). Begitu pula dengan penelitian yag dilakukan oleh Rumengan (2019) menunjukkan bahwa ada hubungan yang bermakna antara akses pelayanan dengan pemanfaatan pelayanan kesehatan. Responden yang memiliki kategori akses pelayanan yang jauh terdapat 10 responden $(23,3 \%)$ yang tidak memanfaatkan puskesmas sedangkan yang memanfaatkan puskesmas sebanyak 33 responden (76,7\%). Responden dengan akses pelayanan yang dekat terdapat 95 responden $(79,2 \%)$ yang tidak memanfaatkan puskesmas sedangkan yang memanfaatkan sejumlah 25 responden $(20,8 \%)$. Artinya faktor jarak menjadi kendala bagi masyarakat untuk menjangkau puskesmas sehingga kunjungan masyarakat yang tempat tinggalnya dekat lebih banyak dari penduduk yang tempat tinggalnya jauh (Rumengan, Januraga and Indrayathi, 2019).

Hasil penelitian ini bertentangan dengan penelitian yang dilakukan oleh Cahyani (2019) bahwa tidak ada hubungan aksesibilitas dengan pemanfaatan pelayanan kesehatan dengan hasil p-value $1>0,05$ (Cahyani, 2019). Begitupun dengan penelitian yang dilakukan oleh Hidayah (2020) yang menunjukkan bahwa tidak ada hubungan antara aksesibilitas dengan pemanfaatan pelayanan kesehatan dengan $p$ value $=0,471$. Berdasarkan temuan diketahui bahwa 65 responden aksesibilitas terjangkau didapat mayoritas memanfaatkan puskesmas 50 
responden $(76,9 \%)$ sedangkan dari 34 responden aksesibilitas tidak terjangkau didapat mayoritas memanfaatkan 29 responden $(85,3 \%)$ sedangkan (Hidayah et al., 2020).

\section{PENUTUP}

Usia (p-value 0,039) dan aksebilitas pelayanan pengobatan $(p$-value 0,020$)$ memiliki hubungan dengan keputusan pemilihan pelayanan pengobatan sedangkan pendidikan $(p-$ value 0,537$)$ sedangkan status pekerjaan ( $p$-value 0,145 ) tidak memiliki hubungan dengan keputusan pemilihan pelayanan pengobatan. Oleh karena itu, diperlukan upaya pemerataan pembangunan khususnya pada infrastruktur baik internal maupun eksternal dari suatu pelayanan kesehatan, meningkatkan kualitas mutu pelayanan kesehatan, rutin melakukan monitoring dan evaluasi dalam bentuk audit mutu internal dan akreditasi serta kredensialing di fasilitas pelayanan kesehatan, meningkatkan teknologi informasi di fasilitas pelayanan kesehatan agar memudahkan bagi tenaga kesehatan maupun pasien dalam proses pelayanan, pemerintah mengupayakan tata kelola fasilitas pelayanan kesehatan semaksimal mungkin, meningkatan kuantitas SDM kesehatan yang berkualitas, penetapan tarif pelayanan yang sesuai dengan regulasi yang ada, melengkapi sarana prasarana, serta meningkatkan keterlibatan masyarakat untuk aktif dalam UKBM, dan membangun kemitraan lintas sektor.

\section{DAFTAR PUSTAKA}

Cahyani, I. 2019. Faktor-Faktor Yang Berhubungan Dengan Pemanfaatan Pelayanan Antenatal Care di Puskemas Trucuk I Kabupaten Klaten. Tesis. Semarang: Universitas Negeri Semarang.

Fatimah, S. \& Indrawati, F. 2019. Faktor Pemanfaatan Pelayanan Kesehatan di Puskesmas', Higeia Journal of Public Health Research and Development, 1(3): 84-94.

Hidayah, R. 2020. Determinasi Pemanfaatan Puskesmas oleh Masyarakat di Puskesmas Landasan Ulin Tahun 2020. 1-8.
Irawan, B. \& Ainy, A. 2018. Analisis Faktor-Faktor yang Berhubungan dengan Pemanfaatan Pelayanan Kesehatan pada Peserta Jaminan Kesehatan Nasional di Wilayah Kerja Puskesmas Payakabung, Kabupaten Ogan Ilir. Jurnal Ilmu Kesehatan Masyarakat, 9(3): 189197.

Jane M. Pangemanan, Nova H. Kapantow, J. H. L. 2014. Hubungan antara Karakteristik Ibu Hamil dengan Pemanfaatan Pelayanan K1 dan K4 di Puskesmas Motoling Kabupaten Minahasa Selatan. Kesehatan Masyarakat Universitas Sam Ratulangi Manado, 2(1): 1-8.

Kurniasih I, S. Y. 2018. Faktor yang Mempengaruhi Kelompok Lanjut Usia Dalam Pemilihan Fasilitas Kesehatan Tingkat Pertama di Bantul Yogyakarta. Medika Respati: Jurnal Ilmiah Kesehatan, 13(1): 1-7.

Londo, J. P., Tucunan, A. A. T. \& Maramis, F. R. R. 2017. Hubungan antara Karakteristik Peserta BPJS Kesehatan dengan Pemanfaatan Pelayanan Puskesmas di Wilayah Kerja Puskesmas Tahuna Barat. Jurnal Kesmas, 6(3): 1-7.

Mamik. 2013. Organisasi dan Manajemen Pelayanan Kesehatan dan Kebidanan. Surabaya: Prins Media Publishing.

Naumi, M. 2018. Determinan Pemanfaatan Pelayanan Kesehatan oleh Peserta Penerima Bantuan Iuran (PBI) di Puskesmas Desa Lalang Kecamatan Medan Sunggal tahun 2018. Skripi. Medan: Universitas Sumatera Utara.

Notoatmodjo. 2007. Ilmu Kesehatan dan Perilaku. Jakarta: Prins Media Publishing.

Ratnasari, G. 2018. Hubungan Ketersediaan Fasilitas, Keramahan, Lama Pelayanan, Usia dan Tingkat Pendidikan Terhadap Pemilihan Tempat Pemberi Pelayanan Kesehatan. Skripsi. Semarang: Universitas Diponegoro.

Riskesdas. 2018. Badan Penelitian dan Pengembangan Kesehatan Kementerian RI. Jakarta.

Rumengan, I. A., Januraga, P. P. \& Indrayathi, P. A. 2019. Faktor-Faktor yang Berhubungan dengan Keinginan Perpindahan Fasilitas Kesehatan Tingkat Pertama pada Peserta JKN Mandiri di Kota Denpasar tahun 2017. Arc. Com. Health, 6(1): 1-8.

Sampeluna, N., Balqis \& Hamzah, A. 2013. Faktor yang Berhubungan dengan Pemanfaatan Pelayanan Kesehatan di RSUD Lakipadada Kabupaten Tana Toraja. Jurnal AKK, 2(3): 22-28. 
Sutana, I. G. 2021. Seni Mendeteksi Penyakit Melalui Lidah Dalam Budaya Pengobatan Tradisional Tiongkok. Jurnal Yoga dan Kesehatan, 4(1): 1120.

Tampi, J. 2016. Hubungan antara Pendidikan, Pendapatan dan Pekerjaan dengan Pemanfaatan Pelayanan Kesehatan di Rumah Sakit Umum Daerah Manembo-Nembo Bitung 2015. Jurnal Kesmas, 5(1): 1-6.
Yuliana, P. 2013. Hubungan Karakteristik Keluarga dan Jenis Penyakit Terhadap Pemanfaatan Pelayanan Kesehatan. Journal of the Mining Institute of Japan, 83(947): 421-423.

Yulianti, E., B.M, S. \& Indraswari, R. 2021. Pengaruh Aksesibilitas Terhadap Praktik Antenatal Care pada Ibu. Jurnal Kesehatan Masyarakat, 9(1): 133-142. 